\title{
Aging, Physical Activity, and Disease Prevention
}

\author{
Ben Hurley ${ }^{1}$ and Iris Reuter ${ }^{2}$ \\ ${ }^{1}$ Department of Kinesiology, School of Public Health, University of Maryland, College Park, MD 20742, USA \\ ${ }^{2}$ Justus-Liebig University Giessen, 35390 Giessen, Germany
}

Correspondence should be addressed to Ben Hurley, benhur@umd.edu

Received 21 April 2011; Accepted 21 April 2011

Copyright (๑) 2011 B. Hurley and I. Reuter. This is an open access article distributed under the Creative Commons Attribution License, which permits unrestricted use, distribution, and reproduction in any medium, provided the original work is properly cited.

Although no amount of physical activity can stop the biological aging process, regular exercise can counteract some of the adverse physiological, psychological, and cognitive consequences of aging [1]. Age and physical inactivity are primary and secondary (indirect) risk factors for a long list of adverse chronic conditions [2,3], whereas increasing physical activity from midlife to old age results in reduced rates of chronic disease and death $[3,4]$.

Our Call for Papers was driven by a growing body of evidence showing strong associations between physical inactivity and age-related chronic disease, as well as reductions in risks or incidence of chronic disease with exercise training [1]. Despite the overwhelming evidence for the role of physical activity in reducing the incidence of mortality, morbidity, and quality of life in chronic disease, a relatively small portion of the population are physically active worldwide [5] and even fewer older adults exercise regularly with sufficient intensity, duration, and frequency to receive optimal benefits for disease prevention [1]. Physical inactivity is especially prevalent in highly developed countries [5]. For this reason, more research is needed to understand and overcome barriers for habitual exercise and sport participation (see 3rd paper in this issue).

A recent study ordered reasons for participating in exercise programs and found that social aspects followed by the intent to improve physical fitness and/or prevent chronic diseases ranked among the highest reasons in older adults. With the increasing number of elderly, especially in the highly developed countries, it is important, yet challenging, to offer attractive and accessible physical activity programs to elderly. Qualified supervision, medical evaluations, and evidence-based individualized exercise prescriptions are also important for older sedentary adults, particularly those with underlying cardiovascular disease [6]. Besides cardiovascular and metabolic disease prevention, physical activity might also help reduce the risk of dementia $[7,8]$ and maintain cognitive function [9]. Since the risk of dementia is strongly associated with age and the number of adults surviving to advanced age will increase markedly in the near future, preventive measures become increasingly important. In this context, there is even some evidence that biological aging of the brain might be slowed down and that brain areas most affected by the aging process might benefit most from regular exercise [10].

This special issue covers a wide array of topics on the aging and physical activity and their relationship to disease and disability prevention. The papers show how aging and physical activity are associated with disability, mortality, behavioral change, home-based counseling interventions, bone and connective tissue health, telomere biology, Parkinson's disease, diabetes, hypertension, cancer, inflammation, antioxidants, sleep apnea, and cognitive function.

The first paper investigates the impact of physical activity on disability in Mexico and the USA The second paper focuses on the relationship between physical activity and mortality rates over a 7-year period in the UK The influence of aging on social cognitive characteristics associated with physical activity and whether improvements in psychosocial factors influence age-related declines in physical activity are discussed in the third paper. The fourth paper assessed the qualities of a counseling intervention on sustaining a physically active lifestyle. The authors of the fifth paper provide a review of the potential benefits of aerobic exercise training and whole-body vibration training on bone mineral density in older populations and discuss possible mechanisms for effects of each intervention. A review of the bone mineral density literature is also highlighted in the sixth paper, but with a focus on how it applies to physical performance and 
other components of body composition. The risk of osteoporosis is described in the seventh paper by assessing the relationship of physical activity, hip fractures, and disability from hip fractures. The eighth paper highlights the role of exercise on the prevention and treatment of osteoarthritis, whereas the ninth paper explains the benefits of both aerobic and resistance exercise training for patients with rheumatoid arthritis. The authors of the tenth paper show how physical and leisure activity can help counteract the association of wheelchair use and poor health perception. The eleventh papre describes the relationship between physical activity and telomere biology as it applies to age-related diseases and longevity. A flexibility and relaxation program is compared to regular walking versus a Nordic walking program in patients with Parkinson's disease in the twelfth paper. The authors of the thirteenth paper review the literature on resistance training and glucose tolerance with applications to diabetes risk in older adults and potential mechanisms of action. The fourteenth paper investigates the effects of aerobic exercise training on the formation of a signaling molecule that influences vascular tone known as eicosanoids. The fifteenth paper reviews the literature on the use of strength training as an intervention to offset some of the deleterious side effects of hormone therapy used by prostate and breast cancer patients. The sixteenth paper studied the role of specialized G-proteins that increase cAMP known as melanocortin 3 receptors on the anti-inflammatory process of resistance training. The antioxidant potential of Tai Chi training is explained in the seventeenth paper, and the last paper describes the role of cognitive function on lower-body physical performance in older African American women.

Ben Hurley Iris Reuter
[6] M. Borjesson, A. Urhausen, E. Kouidi et al., "Cardiovascular evaluation of middle-aged/senior individuals engaged in leisure-time sport activities: position stand from the sections of exercise physiology and sports cardiology of the European Association of Cardiovascular Prevention and Rehabilitation," European Journal of Cardiovascular Prevention \& Rehabilitation. In press.

[7] R. D. Abbott, L. R. White, G. W. Ross, K. H. Masaki, J. D. Curb, and H. Petrovitch, "Walking and dementia in physically capable elderly men," Journal of the American Medical Association, vol. 292, no. 12, pp. 1447-1453, 2004.

[8] E. B. Larson, L. Wang, J. D. Bowen et al., "Exercise is associated with reduced risk for incident dementia among persons 65 years of age and older," Annals of Internal Medicine, vol. 144, no. 2, pp. 73-81, 2006.

[9] D. E. Barnes, K. Yaffe, W. A. Satariano, and I. B. Tager, "A longitudinal study of cardiorespiratory fitness and cognitive function in healthy older adults," Journal of the American Geriatrics Society, vol. 18, no. 2, pp. 459-465, 2003.

[10] S. J. Colcombe, K. I. Erickson, N. Raz et al., "Aerobic fitness reduces brain tissue loss in aging humans," Journals of Gerontology-Series A, vol. 58A, no. 2, pp. 176-180, 2003.

\section{References}

[1] W. J. Chodzko-Zajko, D. N. Proctor, M. A. Fiatarone Singh et al., "American college of sports medicine position stand. Exercise and physical activity for older adults," Medicine and Science in Sports and Exercise, vol. 41, no. 7, pp. 1510-1530, 2009.

[2] Y. Ostchega, T. B. Harris, R. Hirsch, V. L. Parsons, and R. Kington, "The prevalence of functional limitations and disability in older persons in the US: data from the National Health and Nutrition Examination Survey III," Journal of the American Geriatrics Society, vol. 48, no. 9, pp. 1132-1135, 2000.

[3] D. F. Terry, M. J. Pencina, R. S. Vasan et al., "Cardiovascular risk factors predictive for survival and morbidity-free survival in the oldest-old Framingham Heart Study participants," Journal of the American Geriatrics Society, vol. 53, no. 11, pp. 1944-1950, 2005.

[4] E. Kvaavik, G. D. Batty, G. Ursin, R. Huxley, and C. R. Gale, "Influence of individual and combined health behaviors on total and cause-specific mortality in men and women: the United Kingdom health and lifestyle survey," Archives of Internal Medicine, vol. 170, no. 8, pp. 711-718, 2010.

[5] S. C. Dumith, P. C. Hallal, R. S. Reis, and H. W. Kohl III, "Worldwide prevalence of physical inactivity and its association with human development index in 76 countries," Preventive Medicine. In press. 


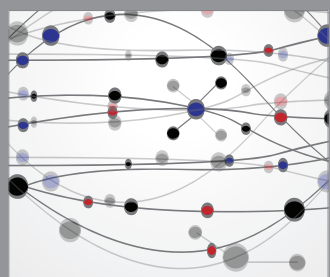

The Scientific World Journal
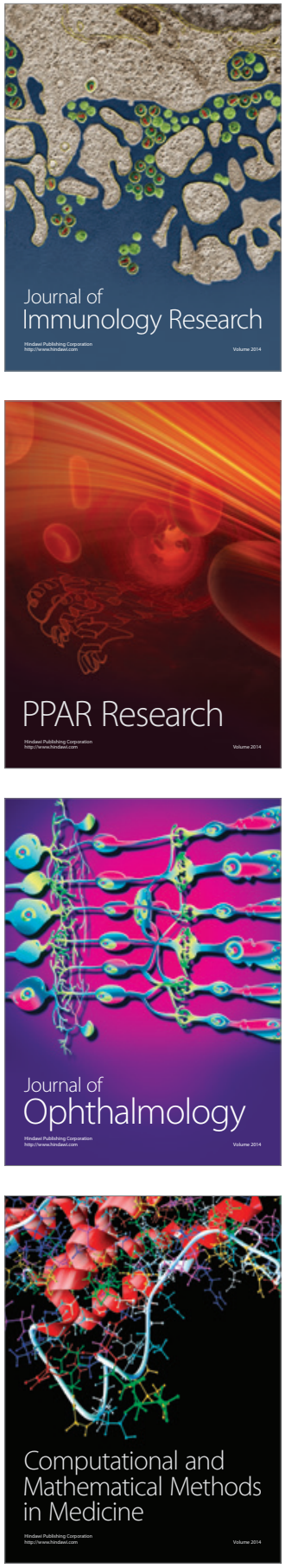

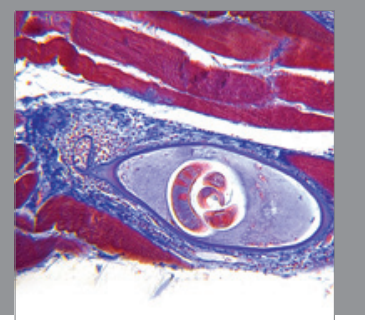

Gastroenterology

Research and Practice
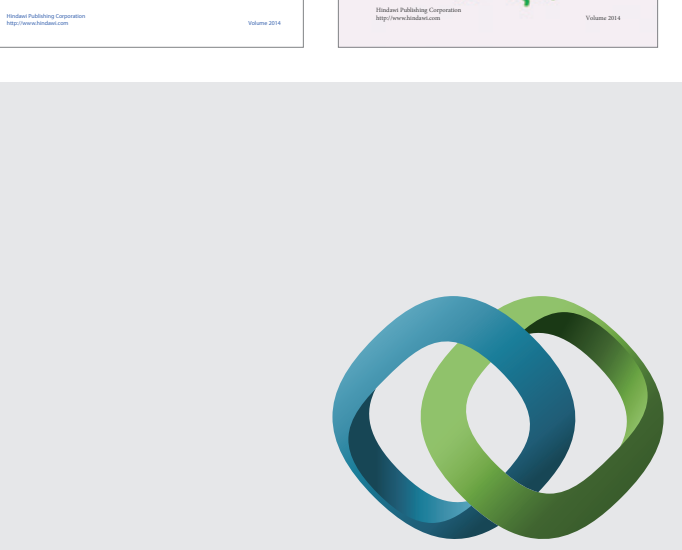

\section{Hindawi}

Submit your manuscripts at

http://www.hindawi.com
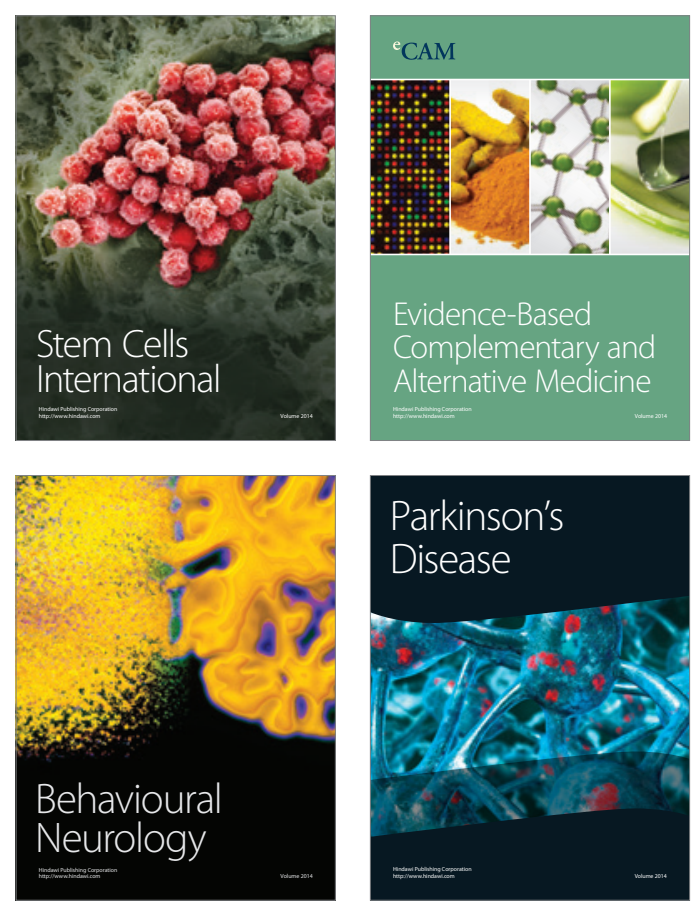

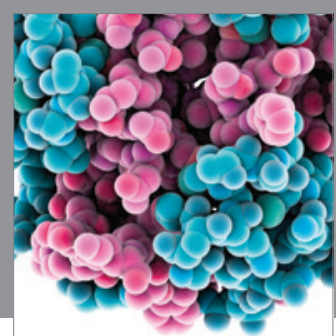

Journal of
Diabetes Research

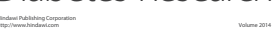

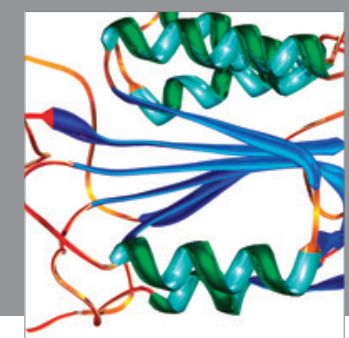

Disease Markers
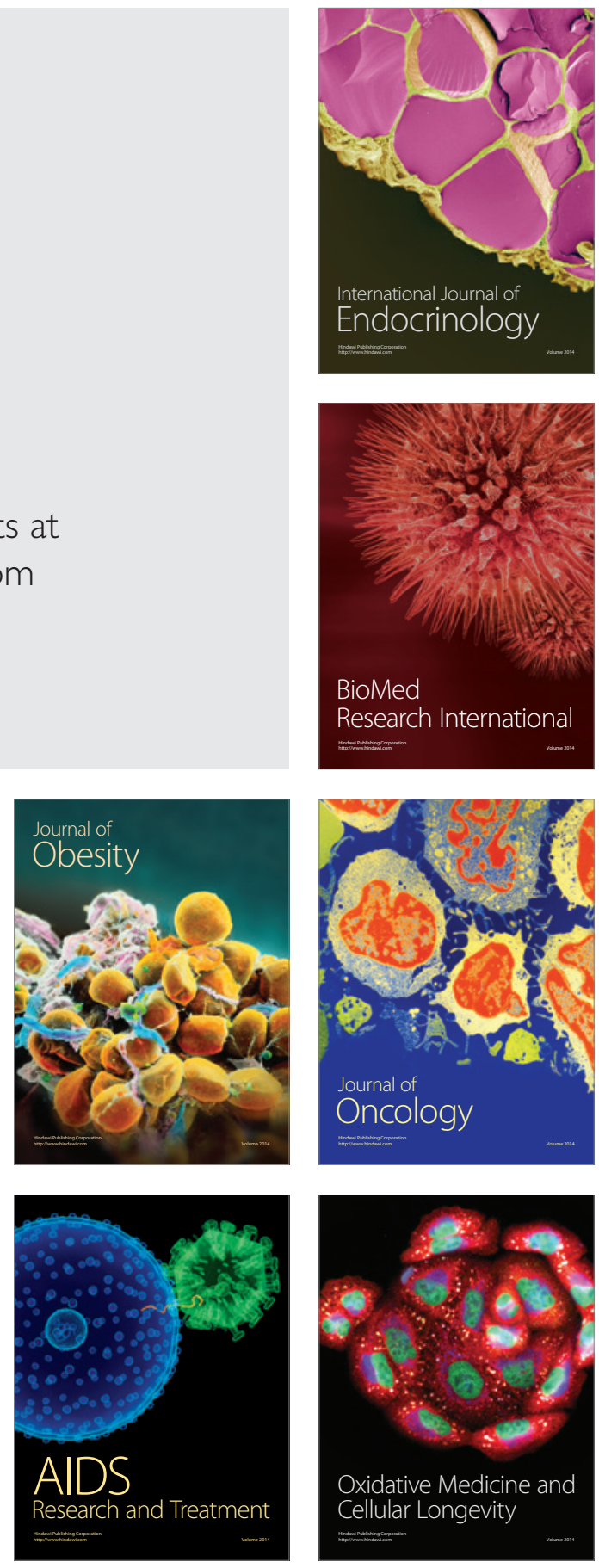